\title{
Building a Dolmen: An ISD Approach to the Management of Innovation
}

\author{
Gabriel J. Costello ${ }^{1}$, Kieran Conboy ${ }^{2}$, Brian Donnellan ${ }^{3}$, Colm Rochford ${ }^{4}$ \\ 1 Galway-Mayo Institute of Technology, gabrielj.costello@gmit.ie \\ 2 National University of Ireland, Galway, kieran.conboy@nuigalway.ie \\ 3 National University of Ireland, Galway, brian.donnellan@nuigalway.ie \\ 4 APC-MGE, Castlebar, Ireland, colm.rochford@apcc.com
}

\begin{abstract}
This paper addresses a "challenge in practice" by describing the initial stage of an information systems development (ISD) project to support the management of innovation within a subsidiary of APC-MGE. To begin with, a review is presented of relevant literature on the management of innovation and on information systems development. The background of the case study is outlined and the advantages of a dialogical action research approach to ISD are discussed. Then the development of a conceptual model using the organizational analysis approach of Multiview2 is described. The work proposes to make a contribution in a number of areas. Firstly it provides empirical evidence of the role of innovation in an organizational transformation and the challenge of designing an information system to support this objective. Secondly it presents an example of using dialogical action research, recently introduced to the MIS discipline by Mårtensson \& Lee, to develop an information system. Future work will involve tracking the implementation of the concept in order to evaluate its impact on the organization.
\end{abstract}

\section{Introduction}

The aim of this paper is to report on the initial stage of an information systems development (ISD) project to support the management of innovation. The work is presented in the context of a case study of APC-MGE, formerly a subsidiary of American Power Conversion (APC), which has recently been acquired by Schneider Electric. The subsidiary is located in Ireland's Border, Midland and Western (BMW) region. This region is designated by the European Union (EU) as Objective 1: a less well developed area that qualifies for additional structural funds under the EU state aid scheme. The national context is Ireland, which in recent decades has leapfrogged from a traditional agrarian economy to a deliberately created information economy (Trauth, 2000). The original impetus was fuelled by foreign direct investment (FDI) from North American multi-national corporations (MNCs) setting up offshore manufacturing facilities to avail of tax incentives, a young educated workforce and proximity to their growing number of European customers. However, this initially successful model is increasingly being threatened by the low cost economies of Eastern Europe, India and China. Ireland is now entering a new era which, according to Porter (2003), requires a transition to an innovation economy.

The paper proposes to answer the following research question: How can ISD support the management of innovation in this context? The approach is that of a 
dialogical action research, recently proposed to the MIS community by Mårtensson \& Lee (2004), that involved "reflective one-on-one dialogues" between the Plant Manager of the corporate subsidiary and the IS researcher. The research proposes to make a contribution to practice by examining the role of IS in supporting the development of an innovative supply chain organization. The paper now proceeds as follows. Firstly a literature review is provided on innovation management and information systems development (ISD). The background and context of the case study is then presented. Next the research approach is outlined and the scope of the research question and data collection are described. Following this, the initial ISD concept is illustrated and implications for practice and research are discussed. Finally the conclusions of the study are presented and suggestions made for future work.

\section{Literature Review}

This section will provide a short review of the main body of literature and theoretical frameworks in which this work is based: namely management of innovation and information systems development.

\subsection{Management of Innovation}

One of the main challenges for an organization that is committed to innovation is the creation and management of an innovative culture. This task is also being spoken of as the challenge of generating an organizational "climate" with the increasing evidence of its positive link to innovation effectiveness (Leavy, 2005). According to Zien \& Buckler (2004) successful companies create a culture where everyone participates in innovation and where it is seen as the fundamental way to provide value to customers. Hertzberg's (2003) seminal work on motivation found that people are "motivated by interesting work, challenge, and increasing responsibility". Good management and working conditions will help to ensure that they do not become dissatisfied but will not meet their deep-seated need for growth and achievement.

Tidd et al. (2005 p 138) propose that innovation must not be seen as a lottery but as a continuous improvement process and point out that, based on recent research on innovation successes and failures, a number of models have been developed to help assess innovation management performance. In order provide some initial reference point for innovation management, they have developed an assessment tool and audit framework. Such self-assessment tools have been widely used in the area of total quality management (TQM) in order to benchmark an enterprise against best in class, for example, the Malcolm Baldrige National Quality Award. The framework proposes five dimensions under which innovation management are to be assessed and profiled: strategy, process, organization, linkages and learning (Tidd et al., $2005 \mathrm{p}$ 568). These dimensions will be discussed further when the IS development is described in section 5 . Some related themes from the innovation literature associated with these dimensions are presented in table1. 
Table. 1 Themes from the innovation literature

\begin{tabular}{|l|l|}
\hline \multicolumn{1}{|c|}{ Attribute } & \multicolumn{1}{c|}{ Characteristic and Reference } \\
\hline Identity & $\begin{array}{l}\text { Treasure identity as an innovative company (Zien \& Buckler, } \\
\text { 2004). }\end{array}$ \\
\hline Employment & $\begin{array}{l}\text { Hire people with a range of abilities, interests and backgrounds } \\
\text { and involve peers heavily in the selection process (Leavy, 2005). }\end{array}$ \\
\hline $\begin{array}{l}\text { Responsibili- } \\
\text { ties }\end{array}$ & Remove control while retaining accountability (Herzberg, 2003). \\
\hline Creativity & $\begin{array}{l}\text { C = K x I x E: Creativity requires Knowledge, Imagination and } \\
\text { Evaluation (Basadur, 2006). Look outside the box (Nemeth, } \\
\text { 2004) }\end{array}$ \\
\hline R\&D & $\begin{array}{l}\text { Not all the smart people work here (Chesbrough, 2003). } \\
\text { R\&D is everyone's business and problems are "golden eggs" } \\
\text { (Basadur, 2004) }\end{array}$ \\
\hline $\begin{array}{l}\text { Suggestions } \\
\text { Schemes }\end{array}$ & $\begin{array}{l}\text { Look for simple focused solutions (Tushman \& O'Reilly, 2004) } \\
\text { to real problems (Drucker, 2003). Use to develop motivation, job } \\
\text { satisfaction and teamwork: not make money (Basadur, 2004). }\end{array}$ \\
\hline Learning & $\begin{array}{l}\text { Give people room to grow , try things out and learn from mis- } \\
\text { takes (Leavy, 2005). 7-3 formula : expect to make wrong deci- } \\
\text { sions 3 times out of 10 (Tushman \& O'Reilly, 2004). }\end{array}$ \\
\hline Management & $\begin{array}{l}\text { Place people and ideas at the heart of management philosophy } \\
\text { (Leavy, 2005). Managers are "symphony conductors" not army } \\
\text { generals and strategy flows from bottom up (Tushman \& } \\
\text { O'Reilly, 2004). People do not resist change : they resist being } \\
\text { changed (Herzberg, 2003). }\end{array}$ \\
\hline Motivation & $\begin{array}{l}\text { People are "motivated by interesting work, challenge, and in- } \\
\text { creasing responsibility" (Herzberg, 2003). A-rated motivations } \\
\text { and B-rated capabilities are better than visa-versa (Katz, 2004). }\end{array}$ \\
\hline
\end{tabular}

We will now proceed to examine the ISD literature in the light of our research objective: to investigate how ISD can facilitate the management of innovation.

\subsection{Information Systems Development}

Throughout the early years of computing from the 1940s to 1960s, ISD was a highly ad hoc and unstructured activity (Colter, 1982; Ward, 1992) with formal methods only being introduced in the following decades as systems technology became more advanced, complex and difficult to develop. These methods were quite successful in so far as they provided a structured means of documenting and implementing technical specifications and functionality. However, while the fulfillment of technical requirements is indeed important, the development environment faced by organizations is much different from that of the 1960s and 1970s, where such a narrow focus on technical engineering is no longer appropriate. Firstly, and significantly for this study, the fast changing nature of the business environment is identified as one of the main reasons why traditional ISD methods are obsolete and there is a need "for new and radical approaches to ISD" (Avison \& Fitzgerald, 2003). In this environment the traditional, large-scale, long-timeframe, multiple-phased, formalized approaches are 
being challenged by the "faster metabolism" (Baskerville \& Pries-Heje, 2004) of modern organizations, the pressure to finish development "yesterday" (Overmyer, 2000), and other traits which reflect the reality of contemporary business. Secondly, many researchers contend that the "context" is of fundamental importance to the development process and that the uniqueness of each situation requires both awareness and detailed understanding (Boehm, 1981; Brooks, 1987; Glass, 1991). These authors were critical of the technical rationality that emerged from information engineering methodologies, and were of the opinion that over emphasis on computer-based artifacts resulted in a neglect of the social and contextual aspects of ISD. In particular, much research focuses on the inability of ISD methods to handle people factors (Avison \& Fitzgerald, 2003).Two contextual areas are emphasized: the technological context, both internal and external in which the ISD is taking place, and the organization culture which has a significant influence on how the ISD can be approached.

There is a general consensus among the ISD community that older methods have ignored the issues discussed above. Most methods are still founded on concepts that originated over 30 years ago, and there is a distinct need to "update the tenses" (Fitzgerald, 2000). There are however, some initiatives which are exceptions to this general rule. The emergence of "lightweight" or "agile" family of methods (Fowler \& Highsmith, 2001; Beck, 1999; Schwaber \& Beedle, 2002) are based on short iterations, minimal processes and constant developer interaction, all of which address some of issues plaguing ISD. Fitzgerald et al. (2002) propose the concept of "method-in-action" which differentiates between the generic text-book method and the uniquely enacted context-based method that is actually implemented in practice. They argue that successful implementation depends more on the social and technological "contextual factors" than on the method that is used. This concept also raises connotations relating to innovation which is of particular relevance in this study. In contrast to the rather negative approach of problem-solving your way out of an unwanted situation (see Yourdon (1997) for terms associated with ISD such as 'firefighting' and 'death-march'), the method-in-action concept views change as an opportunity to creatively 'form a new context'.

Another significant influence on the ISD field has been the Multiview methodology which has been in development since 1985, a time when the area of ISD methodologies was described as a jungle (sic) (Avison \& Fitzgerald, 2003). The initial methodology was refined based on feedback from a number of action research projects that criticized its implicit adherence to a waterfall structure, resulting in what is now known as Multiview2, which Avison \& Fitzgerald propose is more usefully seen as "a metaphor which is interpreted and developed in a particular situation" rather than being a detailed and prescriptive set of actions. There was also a realization that the ISD world had changed significantly since the mid-eighties due to developments in ICT, organizational forms and business processes. Figure 1 illustrates the Multiview2 framework as consisting of four parts that are mediated through the ISD process itself: organizational analysis, socio-technical analysis and design, technical design and construction, and information modeling (acting as a "bridge between the other three, communicating and enacting the outcomes in terms of each other"). 


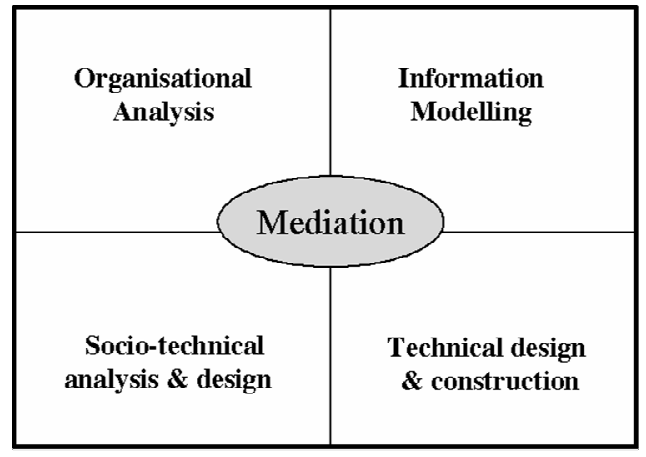

Fig. 1. The Multiview2 framework adapted from Avison and Fitzgerald (2003)

In the context of this paper, the most significant quadrant is "organizational analysis" which is focused on identifying the reasons why the organization requires the IS and understanding the business and social context. The aim of this process is to obtain "an appreciation of the purposeful activity that the information system is to support". It is also important to realize that the authors of Multiview2 insist that the methodology continues to evolve and expect additional iterations based on feedback from "further action research and in-depth case studies" (Avison et al., 1998). Having presented an overview of the literature, the paper will now provide a description of the context: the company case in which the ISD is situated followed by the research approach that is being taken in the study.

\section{Case Study}

The case study is based in APC, Ireland, a subsidiary of the American Power Conversion (APC) Corporation. The Corporation entered a major period of transition in the first quarter of 2007 with completion of its acquisition by Schneider Electric and the formation of a new division: APC-MGE. As the main part of this study was developed before the acquisition, this section will focus on providing a background to the APC context in which the work was carried out. APC designs, manufactures and markets back-up products and services that protect hardware and data from power disturbances. The explosive growth of the Internet has resulted in the company broadening its product offerings from uninterruptible power supplies (UPS) to the high-end InfraStruXure ${ }^{\mathrm{TM}}$ architecture in order to meet the critical availability requirements of internet service providers (ISP) and data-centers. However, recent financial reports have stressed that the company needs to implement significant improvements in manufacturing and the supply chain. According to these reports, the company must work to develop a "lean, customer-centric, ambidextrous organization" in order to reach "optimal efficiencies in our processes" (Results APCC 2006).

APC has two locations in the West of Ireland that serve the European, Middle East and Africa (EMEA) region. The Manufacturing Operations site, based in Castlebar, employs approximately 100 people while a number of functions including 
sales, information technology, business support and research and development (R\&D) are situated in Galway with a workforce of approximately 300. The primary management information system employed by APC is Lotus Notes, a collaborative software system that manages its knowledge flows. It provides a tightly controlled environment for asynchronous group work; where collaborators can have different or independent work patterns. The strength of the MIS function in APC was viewed as an important advantage by Schneider in their acquisition analysis and APC's "intimacy with information technology" was identified as central to the creation of synergies with Schneider's power solutions subsidiary MGE.

\section{Research Design}

The conclusions by Benbasat \& Zmud (1999) concerning the lack of relevance in IS research was, to put it mildly, a criticism of the discipline. Consequently the initial approach to the case study was closely related to the following recommendation in their paper:

IS researchers should look to practice to identify research topics and look to the IS

literature only after a commitment has been made to a specific topic.

However, we believe that the linear nature of their recommendation does not sufficiently accommodate the dynamics of a real-world corporate environment so we have adopted a more iterative approach, going from practice to literature in a continuous cycle. Initially, the work followed Yin's (1994) description of a case study as an "empirical enquiry that investigates a contemporary phenomenon within its reallife context" and where a "how or why question is being asked about a contemporary set of events over which the investigator has little or no control". The preliminary research aim was to consider the human and technological factors involved in the management of innovation. To this end the following research question was posed based on discussions with APC management and informed by the preliminary literature review.

RQ: How can ISD support the management of innovations in this context?

This paper focuses on the initial stage of the design of an information system, during the period from January to April 2007, using the Multiview 2 framework that is aligned with the Schneider Electric corporate objectives (Schneider Electric, 2005).

\subsection{Ethnographic study - January to December 2006}

The research design was initially formulated to take an inductive approach and followed the recommendation of Benbasat \& Zmud outlined above. The rationale was that, first of all, there was a need to spend time in the organization, observing and listening, in order to get a feel for the situation. Data collection methods during this phase involved: maintaining a log book, reviewing documents and information systems, records, interviews, observations (direct and participant), artifacts and surveys in order to develop a database and body of evidence (Gillham 2000; Yin 1994). A total of 29 unstructured or open interviews were undertaken that involved approximately 60 hours of interview time and 24 days spent in the company sites. 
The interviews were conducted across a wide area of the organization that included: Senior Managers with global, EMEA, and site responsibilities, MiddleManagers, Team Leaders, Engineers and a number of people in general planning roles. In order not to disconcert interviewees at the early stage of the research, it was decided not to use a recording system. However permission was obtained to take notes. To confirm that the researcher had correctly understood the social world in which the research was carried out and that the data were correctly reported, a technique known as "respondent validation" or "member validation" was employed. This involved returning a typed version of the notes to the interviewee for comments and agreement, with the aim of ensuring that they were an accurate representation of the meeting (Kelly \& Murnane, 2005).

\subsection{Dialogical Action Research - January 2007 to April 2007}

Recently, Mårtensson \& Lee (2004) have suggested and described a new form of action research called dialogical AR. Here is a brief description of their approach.

In dialogical action research, the scientific researcher does not "speak science"

or otherwise attempt to teach scientific theory to the real-world practitioner, but

instead attempts to speak the language of the practitioner and accepts him as

the expert on his organization and its problems.

The main contact point during Phase 1 was the Plant Manager of the Castlebar location which involved approximately eleven direct meetings with an estimated seventeen hours of interaction. He is leading the "Innovation Management" project which will run throughout 2007 with two main objectives:

- Establish a culture/climate of innovation in APC Castlebar

- Capture, Manage and Diffuse the Innovations across the wider APC-MGE and Schneider Corporation

There was agreement in January 2007 to move forward using dialogical Action Research with meetings every two weeks in Castlebar. In their paper Mårtensson \& Lee propose that "reflective dialogues outside the organization can help the manager to reflect on, learn from, and remedy managerial problems in the organization". In particular, the discipline of having to take regular timeout in a "time-pressured" manufacturing environment was a major incentive for the Plant Manager to agree to this approach. However the realities of the situation have resulted in a further adaptation of Mårtensson \& Lee's methodology: the research "timeout" consists of finding a quiet place in the building and away from the office. The Plant Manager also considered the framework advantageous since it allowed him to retain control and responsibility for all decisions, implementations and communications. However there are a number of practical risks to this type of longitudinal research in a dynamic changing corporate environment, such as the realities of reorganizations and relocations, which are not pointed out by Mårtensson \& Lee. 


\section{Building a Dolmen using Multiview2}

\subsection{Preliminary Model Development}

This section presents the development of a model to address the requirement to manage innovation in the APC-MGE supply chain subsidiary described in section 3. The model emerged from a number of sources: the innovation management literature; the ISD literature with its emphasis on the primacy of contextual factors; the debates on relevance and alignment in the IS literature, and the dialogical action research interactions that took place within a three month period early in 2007. An innovation assessment, carried out in 2006 using the questionnaire proposed by Tidd et al. (2005), had identified that the subsidiary was a Type 2 firm where they "know they need to change but are unsure about how to bring this about". The Plant Manager recognized that there had been significant innovative activity, especially during a Lean Transformation project, but there was now need for a structured approach to innovation management. In the taxonomy of Tidd et al., this would involve moving initially to a Type firm 3 and finally to Type 4: where a firm sees itself as having the capability to generate and absorb innovation. In order to accomplish this, an MIS would be required to capture and manage the innovations together with a related goal to enable the diffusion of these innovations across the wider Corporation. A preliminary objective was to plan the "2007 Innovation Project" with an associated information system to support the venture. It was decided to use the five dimensions proposed by Tidd et al. as a starting point: strategy, process, organization, linkages and learning. In terms of the information systems development, the Mutiview2 approach was seen to be the most appropriate as the quadrant in Figure 1 entitled "organizational analysis" is focused on identifying the reasons why the organization requires the IS and understanding the business and social context. A sixth dimension IS/IT was also included that follows the advice to "keep technology present" in the organizational analysis (Avison et al., 1998 p 131).

\subsection{Reification - Developing a Metaphor}

A stakeholder analysis was carried out to include the main stakeholders and users of the proposed innovation MIS (Avison \& Fitzgerald, 2003 p 277) and they were identified as: APC-MGE Castlebar personnel, APC-MGE Castlebar management team, APC-MGE Castlebar supply chain partners, APC-MGE Ireland management team, APC-MGE/Schneider peers and APC-MGE/Schneider executive decision makers. Finally the Schneider Annual Report of 2005 was reviewed to check that the innovation project was aligned with the corporate objectives. It was considered that the NEW $^{2}$ Schneider Operating Priorities 2005-2008 third objective "Make people passionate about what they do" was significantly aligned to this project and would be now adopted as the project mission statement. A new dimension "environmental performance", was added based on the alignment analysis (Schneider Electric, 2005). Another important aspect that emerged was the challenge of the communicating the project objectives to the two main audiences: employees in the Castlebar location and the APC-MGE Ireland Management forum. After a number of iterations, and in 
order to facilitate communication, the model underwent a process of "reification" which resulted in the innovation "Dolmen" that is shown in figure 2. Kelly (2005) has suggested that "reification" can contribute to opening "new frontiers" in IS theorization but it must be acknowledged that the concept is the subject of controversial debates in the academic literature which are outside the scope of this paper. However, it is used here solely as a literary device to describe the development of a metaphor for the management of innovation in this context.

This conceptualization aimed to take a number of factors into account:

- cultural context: the "Dolmen" analogy is familiar in the West of Ireland and it gives the message of putting in place a system that will endure. A "Dolmen" (from the Breton for "stone table") is an ancient monument, found in many areas of Europe, consisting of two or more upright large stones that support a horizontal capstone.

- the concept seeks to impart the message that the innovation "culture/climate" is supported by a number of critical dimensions.

- some dimensions are more important than others e.g. strategy and processes being critical.

- some attributes closely depended on each other e.g. strategy and organization.

It was also considered significant that developing the "Dolmen" was aligned with Mintzberg's idea of "strategy as craft" and consistent with his identification of the multiple facets of strategy (Mintzberg, 1987).

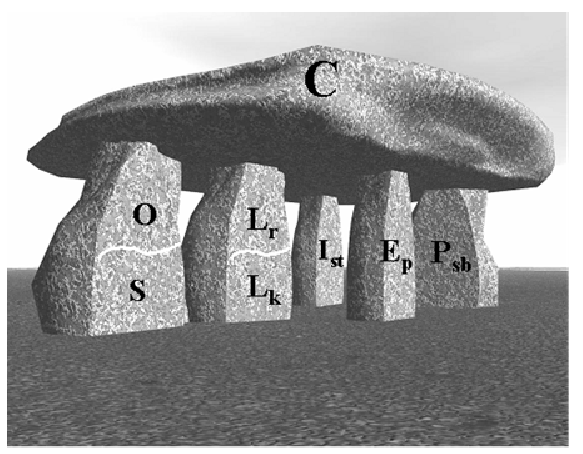

\author{
Abbreviations \\ $\mathrm{C}=$ Innovation Culture/Climate \\ $\mathrm{O}=$ Organisation \\ $\mathrm{S}=$ Strategy \\ $\mathrm{L}_{\mathrm{k}}=$ Links \\ $\mathrm{L}_{\mathrm{r}}=$ Learning \\ $\mathrm{I}_{\mathrm{st}}=$ Information Systems/ Technology \\ $\mathrm{E}_{\mathrm{p}}=$ Environmental Performance \\ $\mathrm{P}_{\mathrm{sb}}=$ Supply Chain /Business processes
}

Fig. 2. A representation of the innovation "Dolmen"

This section has described the initial stages of the development of an information system to support innovation management that is cognizant of the organizational, business and social contextual factors in the APC-MGE subsidiary. Furthermore, an important initial requirement was to ensure that the idea could be communicated to gain the support of the stakeholders which is critical to the success of an innovation project. The approach is aligned with the primacy given in Mutliview2 to organizational analysis $(\mathrm{O})$ and the vision that this "O" perspective is typified by "shared understanding and organizational learning". The paper will now proceed to discuss the implications arising from the "challenge in practice" outlined in this case. 


\section{Discussion}

The previous sections of this paper have provided: an overview of the literature from which this study emerged, the context of the case study, the research approach employed and the initial ISD model constructed from the organizational analysis of the contextual factors. The paper will now proceed to propose some implications of the study for both practice and research.

\subsection{Significance of work and implications for practice}

Innovation management is now seen as an important source of competitive advantage for enterprises and MNC subsidiaries located in Ireland's changing economy. The study is located in the Operations function of an $\mathrm{MNC}$ at a time when the future of supply chain management (SCM) in Ireland is being questioned. It is argued that the evolution of the APC Ireland supply chain is an important case in this context and "commonalities" can provide lessons for other MNCs in the region. Furthermore, the main objective of the study is to examine the role of IS in supporting the innovation agenda. The work has built on a previous innovation audit that identified areas requiring development, and which provided a reference point to begin the transformation to an innovative organization through development of strategy and roadmaps. In addition, the development of the "Dolmen" concept is in line with use of a "Pentathlon" analogy by Goffin and Mitchell (Goffin \& Mitchell, 2005) in their recent work on innovation management.

\subsection{Implications for Research and Limitation of the Study}

This longitudinal study proposes to address a gap in the literature that indicates the need to examine the role of IS in supporting the management of innovation in the context of an MNC subsidiary. The study seeks to build on previous work such as Kelly (2004), which has sought to "understand the potential of ICT to facilitate innovative forms of organizing". In terms of the continuing evolution of Multiview 2, the study has provided empirical evidence of engaging in "concept modeling" before the "information modeling" phase shown in figure 2 which could contribute to further refining the framework. The use of the "Dolmen" analogy follows Avison and Fitzgerald's argument that the framework can "more usefully be seen as a metaphor which is interpreted and developed in a particular situation" and provides an industry based study to examine this contention. In addition, the case study provides empirical evidence of utilizing dialogical action research, recently proposed to the MIS community by Mårtensson \& Lee (2004), in the context of an ISD which is regarded as a core topic in the discipline. The study is limited in that it provides a progress report on the development of the preliminary ISD model to capture the contextual factors of this particular case. The model now needs to be examined further to see if the conceptual framework does help to effect an innovative transformation of the organization and has the capability to communicate the vision to the main stakeholders. 


\section{Conclusions}

This paper has addressed the theme of a "challenge in practice" for the IS community by describing the initial stage of an information systems development (ISD) to support the management of innovation in the APC-MGE Irish subsidiary. To begin with, a brief overview was presented of the main literature on which the study was based. The background of the case study was outlined and the advantages of a dialogical action research approach to ISD were discussed. Then the development of a conceptual model, an innovation "Dolmen", utilizing the organizational analysis quadrant of Multiview2 was described. Future work will involve tracking the implementation to provide evidence of its impact and contribution.

\section{References}

Avison, D. E. and Fitzgerald, G. (2003) Information systems development : methodologies, techniques and tools. McGraw-Hill, London.

Avison, D. E., Wood-Harper, A. T., R.T. Vidgen and Wood, J. R. G. (1998) A further exploration into information systems development: the evolution of Multiview2 Information Technology \& People 11 (2), 124-139.

Basadur, M. (2004) Managing Creativity: A Japanese Model In The Human Side of Managing Technological Innovation: A Collection of Readings (Katz, R., Ed), Oxford University Press, Oxford.

Basadur, M. (2006) The Creativity Equation C = K x I x E ( available on-line at http://www.basadur.com/profile/creativity_eq.htm ).

Baskerville, R. and Pries-Heje, J. (2004) Short Cycle Time Systems Development. Information Systems Journal 14 (3), 237-264.

Beck, K. (1999) Embracing change with extreme programming. IEEE Computer 32 (10), 7077.

Benbasat, I. and Zmud, R. W. (1999) Empirical Research in Information Systems: The Practice of Relevance MIS Quarterly 23 (1), 3-16.

Boehm, B. (1981) Software Engineering Economics Prentice Hall, Englewood Cliffs, NJ.

Brooks, F. (1987) No Silver Bullet: Essence and Accidents of Software Engineering. IEEE Computer 20 (4), 10-19.

Chesbrough, H. W. (2003) Open innovation: the new imperative for creating and profiting from technology Harvard Business School, Boston.

Colter, M. (1982) Evolution of the Structured Methodologies. In Advanced Systems Development Feasibility Techniques (Al, C. E., Ed), pp 73-96, Wiley \& Sons, NY.

Drucker, P. (2003) The Discipline of Innovation. In Harvard Business Review on The innovative Enterprise, Harvard Business School Press.

Fitzgerald, B. (2000) Systems Development Methodologies: The Problem of Tenses. Information Technology \& People 13 (3), 13-22.

Fitzgerald, B., Russo, N. and Stolterman, E. (2002) Information Systems Development: Method-in-Action. McGraw-Hill, Berkshire.

Fowler, M. and Highsmith, J. (2001) The Agile Manifesto. Software Development 9 (8), 28 32.

Glass, R. (1991) Software Conflict: Essays on the Art and Science of Software Engineering. Yourdon Press, Prentice Hall, Englewood Cliffs, NJ. 
Goffin, K. and Mitchell, R. (2005) Innovation Management: Strategy and Implementation using the Pentathlon Framework. Palgrave Macmillan, Houndmills, Basingstoke.

Herzberg, F. (2003) The Best of HBR 1968; One More Time: How Do You Motivate Employees? Harvard Business Review, 87-96.

Katz, R. (2004) The Motivation of Professionals. In The Human Side of Managing Technological Innovation: A Collection of Readings (Katz, R., Ed), Oxford University Press, Oxford.

Kelly, S. (2004) ICT and Social/Organisational Change: A Praxiological Perspective on Groupware Innovation. Ph.D. Thesis, University of Cambridge.

Kelly, S. (2005) New frontiers in the theorization of ICT-mediated interaction? Exploring the implications of a situated learning epistemology. ICIS: International Conference on Information Systems 2005, December 11 - 14 : Las Vegas, Nevada

Kelly, S. and Murnane, S. (2005) Academic Performance Evaluation and the Organisation of Knowledge in the Research-Intensive University. In The Irish Journal of Management incorporating IBAR :Selected papers from the 2005 Irish Academy of Management Conference (Harvey, N., Ed), pp 95-109, Blackhall Publishing, Dublin.

Leavy, B. (2005) A leader's guide to creating an innovation culture Strategy \& Leadership 33 (4), 38 - 45.

Mårtensson, P. and Lee, A. S. (2004) Dialogical Action Research At Omega Corporation. MIS Quarterly 28 (3), 507-536.

Mintzberg, H. (1987) Crafting Strategy. Harvard Business Review (July/August),

Nemeth, C. J. (2004) Managing innovation: When less is more. In The Human Side of Managing Technological Innovation: A Collection of Readings (Katz, R., Ed), Oxford University Press, Oxford.

Overmyer, S. (2000) What's Different about Requirements Engineering for Web Sites? . Requirements Engineering Journal 5 (1), 62-65.

Porter, M. (2003) Irish Competitiveness: Entering a New Economic Era. IMI Top Management Briefing, Dublin, Ireland, 9 October 2003 (available on-line through www.isc.hbs.edu)

Results APCC (2006) American Power Conversion Reports First Quarter 2006 Financial Results. (available on-line through http://www.apcc.com/ accessed June 2006).

Schneider Electric (2005) Schneider Electric 2005 Annual Report (available on-line through http://www.schneider-electric.com/wps/portal/corp/ ).

Schwaber, K. and Beedle, M. (2002) Agile Software Development with Scrum. Prentice-Hall, Upper Saddle River, NJ.

Tidd, J., Bessant, J. and Pavitt, K. (2005) Managing innovation : integrating technological, market and organizational change /. John Wiley \& Sons, Chichester.

Trauth, E. M. (2000) The Culture of an Information Economy: Influences and Impacts in the Republic of Ireland. Kluwer Academic Publishers, Norwell, MA.

Tushman, M. L. and O'Reilly, C. (2004) The Ambidextrous Organization: Managing Evolutionary and Revolutionary Change. In Managing Strategic Innovation and Change: A Collection of Readings (Tushman, M. L. and Anderson, P., Eds), Oxford University Press, Oxford.

Ward, P. (1992) The Evolution of Structured Analysis: Part II- Maturity and its Problems. American Programmer 5 (4), 18-29.

Yin, R. K. (1994) Case study research: design and methods Sage Publications, London Yourdon, E. (1997) Death March. Prentice Hall, Upper Saddle River, NJ.

Zien, K. A. and Buckler, S. A. (2004) Dreams to Market: Crafting a culture of innovation. In The Human Side of Managing Technological Innovation: A Collection of Readings (Katz, R., Ed), Oxford University Press, Oxford. 